\author{
Sindi Ardila Yuliarisma ${ }^{1}$ \\ Darmadi $^{2}$ \\ Pupung Puspita \\ Ningrum $^{3}$ \\ Ayu Safitri ${ }^{4}$ \\ Yohannes Eko Prasetyo ${ }^{5}$ \\ Khoirotun Nisa $^{6}$
}

\section{PERAN ORANG TUA DALAM MENYEIMBANGKAN PSIKOLOGI ANAK PADA PEMBELAJARAN MATEMATIKA MASA COVID 19}

\begin{abstract}
Abstrak
Penelitian ini bertujuan untuk mengetahui peran orang tua dalam menyeimbangkan psikologi anak pada pembelajaran matematika di masa Covid-19. Pentingnya pembelajaran matematika bagi anak membuat orang tua ikut mengambil peran dalam menanamkan konsep matematika kepada anak disamping pengajaran di sekolah. Sejak pandemi Covid-19 semua kegiatan belajar mengajar harus dilakukan sepenuhnya dari rumah. Oleh karena itu, tulisan ini mengkaji tentang bagaimana peran orang tua dalam menyeimbangkan psikologi anak pada pembelajaran matematika masa Covid-19. Metode penelitian ini menggunakan penelitian observasi kualitatif. Data diperoleh dengan wawancara dengan 5 responden yaitu orang tua siswa SD dengan 15 pertanyaan singkat dan 3 jawaban responden pribadi. Populasi penelitian ini adalah orangtua siswa yang terdampak Covid-19. Kesimpulan penelitian ini adalah banyak orang tua menilai bahwa melalui pembelajaran di rumah dapat mempererat hubungan dengan anaknya, begitupun anaknya dinilai dapat melakukan pembelajaran di rumah dengan sangat kurang efektif. Peran orang tua sungguh utama dalam menjaga keseimbangan psikologi akibat tekanan pandemi yang harus melakukan pembelajaran daring. Pemberian motivasi dan pemahaman pandemi serta membantu proses belajar kunci orang tua pada masa kali ini.
\end{abstract}

Kata Kunci: Peran Orang Tua, Pembelajaran di Rumah (daring), Pandemi.

\title{
Abstract
}

This study aims to determine the role of parents in balancing children's psychology in learning mathematics during the Covid-19 period. The importance of learning mathematics for children makes parents take part in imparting mathematical concepts to children in addition to teaching in schools. However, since the Covid-19 pandemic all teaching and learning activities must be carried out entirely from home. Therefore, this paper examines how the role of parents in balancing children's psychology in learning mathematics for children. This research method uses qualitative observational research. Data obtained by interviewing 5 respondents, namely parents of elementary school students with 14 short questions and 3 answers from personal respondents. The population of this study were parents of students who were affected by covid19. The conclusion of this study is that many parents assess that learning at home can strengthen the relationship with their children, as well as their children are considered to be able to do learning at home very less effectively. Through learning at home, parents can see the progress of their children in learning. The role of parents is really the main role in maintaining the psychological balance due to pandemic pressures that have to do online learning. Providing motivation and understanding of the pandemic as well as helping parents learn the keys at this time.

Keywords: Pandemic,The Role of Parents, and Learning at Home (online)

1,2,3,4,5,6) Program Studi Pendidikan Matematika , Fakultas Keguruan dan Ilmu Pendidikan Universitas PGRI Madiun

Alamatemail : cindy12say@gmail.com ${ }^{1}$,darmadi.mathedu@unipma.ac.id², pita.pupung24@gmail.com³ asafitri495@gmail.com ${ }^{4}$,y.eko.p200601@gmail.com ${ }^{5}$, khoirotunnisa635@gmail.com6 


\section{PENDAHULUAN}

Pandemi Covid-19 tidak hanya menyerang terhadap kesehatan fisik namun juga berpengaruh pada kesehatan psikologis. Keadaan ini membuat individu merasa terganggu kesehatan psikologisnya seperti kecemasan, ketakutan, kehawatiran yang berlebihan serta berdampak psikosomatis lainnya. Hal ini juga dialami oleh peserta didik yang sudah terlihat kejenuhan dan kebosanan dengan situasi dan kondisi seperti ini, Selain kesulitan belajar, gangguan kesehatan mental juga akan banyak mempengaruhi keadaan psikis siswa dimana situasi saat ini menuntut siswa untuk secepat mungkin mampu beradaptasi belajar dengan lingkungan dimana mereka hidup sehari-hari. Langkah yang diterapkan oleh pemerintah pada dunia pendidikan saat pandemi Covid-19 ialah dilaksanakannya pembelajaran dengan sistem daring daring (dalam jaringan).

Pembelajaran daring mengakibatkan keterlibatan orang tua dalam menjaga kemaksimalan anak dalam ikut serta dalam pembelajaran khususnya matematika.mengapa demikian? Karena banyak diketahui bahwa pembelajaran matematika mengkhawatirkan sangat banyak peserta didik karena mereka berasumsi bahwa pembelajaran tersebut rumit, membosankan bahkan menakutkan padahal sebenarnya kita harus menguasai matematika karena ilmu bersifat sistematis, logis, kritis dan dibawa pada kehidupan masyarakat untuk menyelesaikan persoalan dengan mudah. Pada situasi seperti ini orang tua dituntut untuk membimbing anak-anaknya agar anak tetap bersemangat dan mengurangi tekanan mental dan stress karena perubahan pola belajar yang tidak kondusif. .

Dewasa ini psikolgi adalah disiplin ilmu yang bermanfaat bagi kehidupan manusia. Psikologi dapat menyentuh hampir seluruh aspek dimensi kehidupan manusia. Mulai dari teori-teori dan riset psikologi telah teraplikasikan kesegala lapangan kehidupan seperti bidang kesehatan, pembelajaran, perkembangan, pendidikan, ekonomi, politik dan sebagainya. Bapak Pof. Dr. H. Kadirun Yahya, M.Sc., ahli tasawuf (Hanna Djumhana Bastaman,1997 ) bahwa " psikologi dimana saja terpakai, walau engkau sebagai apa saja diatas dunia ini ...". maka dari itu harus diperlukan peran-peran penting terhadap seorang anak-anak dalam perkembangan psikologi mereka terlebih saat pandemi seperti saat ini. Faktor internal dan faktor eksternal yang mampu menjadikan mereka paham akan pandemi dan juga dapat mengurangi tekanan psikologi anak.

Peran orang tua sangat diperlukan utuk memberikan edukasi kepada anak-anaknya yang belum bisa memahami tentang pandemi yang sedang mewabah untuk tetap berdiam diri dirumah agar tidak terlular dan menularkan wabah pandemi ini. Beberapa peran lain orang tua selama pandemi ialah sebagai berikut:

1. Orang tua memiliki peran sebagai guru di rumah, yang di mana orang tua dapat membimbing anaknya dalam belajar secara jarak jauh dari rumah.

2. Orang tua sebagai fasilitator, yaitu orang tua sebagai sarana dan pra-sarana bagi anaknya dalam melaksanakan pembelajaran jarak jauh.

3. Orang tua sebagai motivator, yaitu orang tua dapat memberikan semangat serta dukungan kepada anaknya dalam melaksanakan pembelajaran, sehingga anak memiliki semangat untuk belajar, serta memperoleh prestasi yang baik.

4. Orang tua sebagai pengaruh atau director.

\section{METODE}

Penelitian ini menggunakan metode kualitatif. (Mulyadi, 2011) Metode kualitatif merupakan pendekatan penelitian yang mewakili paham naturalistik (fenomenologis). Selain itu, menurut Sugiyono metode penelitian kualitatif yang digunakan untuk meneliti pada objek yang alamiah yang dimana peneliti adalah sebagai intrumen kunci, teknik pengumpulan data dilakukan secara gabungan, analisis data bersifat induktif dan hasil peneliti kualitatif lebih menekankan makna daripada generalisasi (Prasanti, 2018). Penelitian ini menggunakan studi kasus eksplorasi yang bertujuan untuk mendapatkan informasi bagaimana pembelajaran matematika selama pandemi Covid-19 dan apa kendalanya. Metode pengumpulan data menggunakan wawancara terstruktur dan dijadikan data primer. Sedangkan data sekunder berupa studi pustaka. Wawancara bertujuan untuk menghemat waktu dan membatasi efek pewawancara bila sejumlah pewawancara yang berbeda terlibat dalam penelitian. Analisis data tampak lebih mudah sebagaimana jawaban yang dapat ditemukan dengan cepat. Umumnya, pengetahuan statistik penting dan berguna untuk menganalisis jenis wawancara ini (Rachmawati, 2007). Selan itu, wawancara ini dilakukan secara terstruktur, dengan 
memberikan 17 pertanyaan kepada responden terdiri dari 14 pertanyaan jawab singkat (iya,tidak) dan 3 pertanyaan dengan jawaban penjelasan responden sendiri.Wawancara rata-rata dilangsungkan dalam waktu 10 menit. Wawancara dilakukan langsung dengan responden. Penelitian ini mewawancarai 5 responden, yaitu orang tua dari siswa SD kelas 1-5.

\section{HASIL DAN PEMBAHASAN}

Penelitian ini bertujuan untuk mengetahui peranan orang tua dalam meyeimbangkan psikologi anak di masa pandemi pada pembelajaran matematika.untuk mengatasi terputusnya dunia pendidikan maka menteri pendidikan memberikan keputusan untuk memberlakukan pembelajaran di rumah. Pembelajaran dirumah sering disebut dengan daring sebagai upaya pemutusan rantai penularan dan penyebaran Covid-19.

Berikut ini merupakan hasil wawancara yang dilakukan dengan orang tua dengan sasaran siswa SD yang ikut serta mendidik dan membimbing anaknya sewaktu pembelajaran daring selama ini.

Pertanyaan-pertanyaan yang diajukan kepada responden (orang tua siswa SD)

Tabel 1 Hasil Wawancara Subjek

\begin{tabular}{|c|c|c|c|}
\hline No & Pertanyaan & Ya & Tidak \\
\hline 1 & $\begin{array}{l}\text { Pembelajaran dirumah apakah sangat efektif } \\
\text { untuk diterapkan }\end{array}$ & 1 responden & 4 responden \\
\hline 2 & $\begin{array}{l}\text { Melalui pembelajaran di rumah dapatkan } \\
\text { meningkatkan kualitas pembelajaran anak }\end{array}$ & - & 5 responden \\
\hline 3 & $\begin{array}{l}\text { Pembelajaran di rumah lebih menguntungkan } \\
\text { daripada pembelajaran biasa }\end{array}$ & 1 responden & 4 responden \\
\hline 4 & $\begin{array}{l}\text { Melalui pembelajaran dirumah dapat } \\
\text { mempererat hubungan orang tua dengan anak }\end{array}$ & 5 responden & - \\
\hline 5 & $\begin{array}{l}\text { Melalui pembelajaran dirumah orang tua dapat } \\
\text { melihat perkembangan anak }\end{array}$ & 5 responden & - \\
\hline 6 & Anak melakukan di rumah dengan sangat baik & 1 responden & 4 responden \\
\hline 7 & $\begin{array}{l}\text { Pembelajaran di rumah dapat membantu anak } \\
\text { dalam belajar selama pandemi covid-19 }\end{array}$ & 2 responden & 3 responden \\
\hline 8 & $\begin{array}{l}\text { Selama pembelajaran di rumah, orang tua } \\
\text { selalu membantu anak saat mengerjakan tugas }\end{array}$ & 4 responden & 1 responden \\
\hline 9 & $\begin{array}{l}\text { Sebagai orang tua memberikan motivasi } \\
\text { kepada anak selama berlangsungnya } \\
\text { pembelajaran di rumah }\end{array}$ & 5 responden & - \\
\hline 10 & $\begin{array}{l}\text { Pembelajaran di sekolah memiliki sedikit } \\
\text { pengeluaran }\end{array}$ & 3 responden & 2 responden \\
\hline 11 & $\begin{array}{l}\text { Sebagai orang tua pembelajaran di rumah dapat } \\
\text { meningkatkan pengetahuan Teknologi, } \\
\text { Informasi, dan Komunikasi bagi anak }\end{array}$ & 5 responden & - \\
\hline
\end{tabular}




\begin{tabular}{|c|l|l|l|}
\hline 12 & $\begin{array}{l}\text { Orang tua lebih mudah mengerjakan pekerjaan } \\
\text { rumah jika anak belajar di sekolah }\end{array}$ & - & 5 responden \\
\hline 13 & $\begin{array}{l}\text { Tugas yang diberikan dari sekolah dalam } \\
\text { pembelajaran di rumah tidak begitu sulit, } \\
\text { sehingga orang tua masih mampu membantu } \\
\text { anak dalam menyelesaikan tugasnya }\end{array}$ & 1 responden & 4 responden \\
\hline 14 & $\begin{array}{l}\text { Orang tua merasa senang kepada guru yang } \\
\text { selalu memberikan tugas kepada anak saya }\end{array}$ & - & 5 responden \\
\hline 15 & $\begin{array}{l}\text { Apakah anak mengalami kesulitan dan tertekan } \\
\text { dalam menerima pembelajaran matematika } \\
\text { selama di rumah }\end{array}$ & 5 responden & \\
\hline
\end{tabular}

Selain ke 15 pertanyaan singkat diatas, penulis juga memberikan tiga pertanyaan guna mengetahui pendapat responden mengenai pembelajaran yang dilakukan di rumah. Berikut hasil wawancaranya :

1. Mengapa pembelajaran matematika tidak efektif dilakukan dirumah?

Responden 1 : Karena pembelajaran matematika butuh latihan dan pemahaman lebih dalam sehingga butuh pengajaran guru secara langsung.

Responden 2 : Karena matematika sulit saya saja sekarang tkurang paham yang dulu saya dapat dikleas 4 sekarang dsudah diberikan pada materi kelas 2 karena tuntutan kurikulum dan matematika adalah ilmu pasti sehingga tidak bisa menggunakan ilmu tebak-tebakan.

Responden 3: Karena matematika perlu pemahaman secara bertahap khususnya mereka yang memiliki proses pemahaman yang rendah sehingga mereka perlu bimbingan khusus untuk memahaminya

Responden 4 : Karena matematika identik dengan berhitung, pelajaran ini perlu pemaham lebih untuk menguasai konsep matematika pada setiap materi. Jikalaupun dengan tatap muka saja anak masih sulit memahami bagaimana jika daring akan menjadi lebih sulit.

Responden 5 : karena pelajaran matematika butuh penjelasan secara detail dari guru

2. Bagaimana respon anak anda ketika mendapatkan pembelajaran matematika di rumah?

Responden 1: Anak serasa males ,sulit menerima dan memahami serta lebih mementingkan bermain bersama teman-temannya

Responden 2 : Mengeluh jika terdapat pengurangan dan pembagian karena belum begitu memahami,dan juga jika menemui rumus-rumus anak tidak mau mengaplikasikan

Responden 3 : Terkadang mereka antusias terkadang mereka sudah malas terlebih dahulu untuk belajar dan membaca materi dari materi yang sudah dishare gurunya

Responden 4: Selalu menunda-nunda tugas agar nanti dibantu orang tuanya sehingga terkesan malas

Responden 5 : Mudah marah jika disuruh belajar dan mengerjakan tugasnya dan lebih sering meminta untuk didampingi

3. Sebagai orang tua hal apa yang dapat dilakukan untuk mengatasi sikap anak ?

Responden 1 : Iya, membagi waktu antara pekerjaan dengan mengawasi belajar anak,memberikan motivasi dan pengajaran tentang pandemi serta membuatkan jadwal teratur pembelajaran dan juga menciptakan lingkungan secara kondusif dirumah. 
Responden 2 : Membuat lingkungan nyaman sesuai keinganan anak memberikan waktu istirahat serta menjanjikan membelikan sesuatu yang dia inginkan untuk membangkitkan semangat belajarnya, memberikan contoh masalah sosial yang berkaitan dengan soal-soal yang belum dipahami contohnya tadi pengurangan diperumpakan si anak mempunyai barang kemudian hilang sekian dan sebagainya.

Responden 3 : Menanamkan percaya diri kepada anak, mengenalkan orang-orang sukses karena belajar matematika agar anak semangat belajar.

Responden 4 : Membantu anak dalam mengerjakan tugas jika mengalami kesulitan, tidak terlalu menuntut dan memberikan perhatian lebih agar anak tidak bermalas-malasan.

Responden 5: Sebisa mungkin memenami saat anak mengerjakan tugas dan selalu mendengarkan keluh kesahnya dan memberikan motivasi.

Berdasarkan pernyataan dan hasil jawab singkat pada tabel 1 dapat diketahui pembelajaran dirumah tidak efektif dilakukan khususnya pada pembelajaran matematika. Hal ini dikarenakan pembelajaran matematika ialah pembelajaran dengan ilmu pasti yaitu jawaban benar dianggap benar dan sebaliknya salah juga akan tetap salah tidak akan ada toleransi seperti pembelajaran lain, dan kerap matematika menjadi momok bagi para peserta didik khususnya operasi hitung pengurangan dan pembagian. Pekerjaan orang tua pun juga terganggu karena adanya pembelajaran daring karena orang tua mengawasi kegiatan pembelajaran anaknya walaupun sebenarnya sistem ini mampu membuat erat hubungan anak dengan orang tua serta meningkatkan menaplikasikan IPTEK. Banyak dari orang tua pun membantu memberikan motivasi selama siswa dituntut untuk belajar dari rumah karena himbauan pemerintah mengenai Covid-19, hal ini juga yang membuat tidak sedikit orang tua untuk meluangkan waktunya untuk membantu proses pembelajaran anaknya selama di rumah. Pembelajaran daring dianggap orang tua merasa materi dan tugas-tugas yang diberikan lebih sulit dan terlihat lebih banyak hal ini dikarenakan guru berasumsi bahwa pemberian soal tugas dapat meyakinkan pemantapan pemahaman materi anak.

Orang tua yang setuju jika selama pembelajaran di rumah, orang tua juga ikut membantu mengerjakan tugas yang diberikan oleh guru. Walaun tidak sedikit juga yang merasa menjadi tambahan aktivitas orang tua selain mengerjakan pekerjaan rumah tangga. Hal ini sesuai dengan pendapat Kholil (2020) bahwa mendampingi anak belajar dari rumah, sambil orangtua mengerjakan pekerjaan yang harus diselesaikan dari kantor atau dari rumah memang menjadi tantangan tersendiri, yang perlu diingat adalah orangtua di rumah bukan untuk menggantikan semua peran guru di sekolah. Pemberian motivasi,membantu pemahaman, menciptakan lingkungan kondusif dan membantu pengerjaan tugas-tugas juga diberikan orang tua untuk membangkitkan semangat belajar matematika anaknya.

\section{UCAPAN TERIMAKASIH}

Penulis mengucapkan terima kasih pada Bapak Darmadi selaku dosen pembimbing, orang tua yang selalu mendukung proses penulisan artikel serta reviewer dan penerbit jurnal Universitas Pahlawan yang telah memberi kesempatan kami untuk mempublish karya ini. Semoga karya kami dapat diterima dengan baik di masyarakat serta mampu memajukan sistem pendidikan di tengah pandemic Covid-19.

\section{SIMPULAN}

Pembelajaran dirumah sebenarnya memiliki nilai positif dan juga nilai negatif. Hubungan antara anak dan orang tua akan menjadi lebih erat karena selama pandemi orang tua dan anak saling melakukan kegiatan di rumah sehingga orang tua dan anak menjadi lebih berinterkasi banyak. Namun pandemi ini membuat tekanan baik fisik maupun emosional dan memicu stress bagi anak-anak sekolah terutama pada pembelajaran matematika yang kerap dianggap sebagai momok pelajaran di dunia peserta didik. Pembelajaran daring adalah alternatif yang dilakukan dunia pendidikan untuk mengatasi pembelajaran di masa pandemi saat ini. Orang tualah yang memiliki peran penting pada masa ini karena orang tualah yang mempunyai interaksi banyak saat pembelajaran daring sehingga mereka harus memiliki perlakuan khusus terhadap anak agar mereka mampu memahami kondisi saat ini dan tetap semangat belajar. 
Sehingga peran tua penting dalam pemutusan rantai pandemi lebihnya terhadap keseimbangan psikologi anak khususnya pada pembelajaran matematika. Hal yang dilakukan diantaranya, pemberian pemahaman pandemi, motivasi terus-menerus, pengaturan jadwal yang kondusif antara pekerjaan dengan mengawasi belajar anak, ajak anak berfikit lebih kritis, selalu mendengarkan keluh kesah anak dan memberikan solusinya serta menciptakan lungkungan kondusif untuk belajar anak menjadi lebih nyaman.

\section{DAFTAR PUSTAKA}

Dra. Desmita, M. (2009). PSIKOLOGI PERKEMBANGAN PESERTA DIDIK. Bandung: PT REMAJA ROSDAKARYA.

Haerudin, Cahyani, A., Sitihanifah, N., Setiani, R. N., Nurhayati, S., Oktaviana, V., \& Sitorus, Y. I. (2019). PERAN ORANG TUA DALAM MEMBIMBING ANAK SELAMA PEMBELAJARAN DI RUMAH SEBAGAI UPAYA MEMUTUS COVID-19. Artikel Universitas Singaperbangsa Karawang.

Handayani, N. S. (2020). Keseimbangan pekerjaan keluarga dan kebahagiaan studi metaanalisis. jurnal psikologi, Vol 16 No 2.

Josua, D. P., Sunarti, E., \& Krisnatuti, D. (2020). Internalisasi nilai keluarga dan regulisasi emosi:dapatkah membentuk perilaku sosial remaja? Persona: Jurnal Psikologi Indonesia, volume 9, No 1 Juni 2020 Hal 17-34.

Mulyadi, M. (2011). Penelitian Kuantitatif dan Kualitatif serta Pemikiran Dasar Menggabungkannya. Jurnal Studi Komunikasi dan Media, Vol.15 No.1.

mulyadi, m. (2011). PENELITIAN KUANTITATIF DAN KUALITATIF SERTA PEMIKIRAN DASAR MENGGABUNGKANNYA . jurnal studi komunikasi dan media, volume 5 no. 1.

Prasanti, D. (2018). PENGGUNAAN MEDIA KOMUNIKASI BAGI REMAJA PEREMPUAN. Jurnal Lontar, 13-21.

Rachmawati, I. N. (2007). PENGUMPULAN DATA DALAM PENELITIAN KUALITATIF. Keperawatan Indonesia, 35-40.

Rohmah, E. Y. (2010). PERKEMBANGAN PSIKOLOGIS ANAK MI/SD: STUDI ATAS DAMPAK KEPERGIAN IBU SEBAGAI TKW KE LUAR NEGERI. KODIFIKASIA Jurnal Penelitian Keagamaan dan Sosial-Budaya, Nomor 1 Volume 4 Tahun 2010.

Wiryanto. (2020). Proses Pembelajaran Matematika di Sekolah Dasar di Tengah Pandemi Covid-19. Jurnal Review Pendidikan Dasar:Jurnal Kajian Pendidikan dan Hasil Penelitian, Vol,06.N0 02. 